\title{
Physio-Biochemical basis of Yield and Quality Variation in Turmeric (Curcuma longa L.) Genotypes
}

\author{
Mudit Srivastava*
}

Research scholar, Centre of Advanced Studies, Department of Crop Physiology, Narendra

Deva University of Agriculture \& Technology, Kumarganj, Faizabad-224229(UP), India

*Corresponding author

\begin{abstract}
A B S T R A C T
A set of 17 genotypes of turmeric Curcuma longa L. of N.D.U.A\&T Kumarganj Faizabad were assessed for variation in morphological features, leaf and rhizome essential oil

Keywords

Curcuma longa;

Haldi, Genetic

variability,

Morphological

characterization of

essential oil,

Chemotypes

\section{Article Info}

Accepted:

28 February 2018

Available Online:

10 March 2018 content, yield and quality, curcumin content in rhizome and curcumin yield and potential for curcumin extraction from rhizomes, following their distillation for essential oil extraction. Large variability was recorded in all the features studied. The genotypes demonstrated wide variation in the contents of $\gamma$-terpenene, 1,8 -cineole and $\rho$-cymene in the leaf essential oils and of pinene, myrcene, Ar-curcumene and turmerones in the rhizome essential oils. There were some genotypes which were highly deficient in one or more terpenoids in their leaf and/or rhizome essential oil. The leaf oils of the accessions NDH-7, NDH-8, NDH-9, and NDH-45 were deficient in $\rho$-cymene and Ar-turmerones, Ar-curcumene and Ar-turmerone, Ar-turmerone and $\beta$-turmerone, Ar-curcumene and Arturmerone and $\beta$-turmerone and Ar-curcumene and all turmerones, respectively. The rhizome essential oil of the genotype NDH-14 was highly rich in turmerones and that of NDH-98 was deficient in turmerones, respectively. The genotypes NDH-88, NDH-108 and NDH-118 were identified as high yielding elite resource for both curcumin and leaf oil. The possibility of profitable extraction of curcumin from the essential oil extracted rhizomes was demonstrated.
\end{abstract}

\section{Introduction}

Curcuma longa L. turmeric plant, domesticated in India, is widely cultivated for the production of turmeric powder, which is widely used as spice and food colouring agent and as the resource for curcumin, the main phenolic compound in turmeric. Used in traditional and Ayurvedic medicines as haldi for centuries, curcumin has proven properties of antioxidant and anti-inflammatory agent and induces apoptosis in a variety of cancer cells (Khanna, 1999; Kunnumakkara et al., 2008; Liang et al., 2009; Lin et al., 2008; Moon et al., 2008; Pisano et al., 2008; Srimal, 1997). Recently curcumin has been found to be anti-depressive and hypolipidimic (Bhutani et al., 2009; Jang et al., 2008). Since curcumin is quite safe and exhibits therapeutic efficacy against a variety of clinical conditions, the use of turmeric is expected to expand worldwide. In this context, the available genetic resources 
of $C$. longa require to be evaluated for the identification of most productive lines for direct use and for recombining the favourable characters in them by conventional, genetic engineering and other biotechnological plant breeding tools. This study compares the morphological and chemical features of 17 genotypes of $C$. longa collected in India and identifies some unique and useful lines.

\section{Materials and Methods}

The experiment was carried out on a crop of 17genotypes of $C$. longa land races. The genotypes had been collected from various parts of the rural areas of northern India Uttar Pradesh, Kerala and Bihar. These genetic resources were being maintained in the gene bank. Figure 1 depicts the features of a typical C. longa plant.

\section{Growth conditions}

Using well formed rhizomes genotypes were sown row-wise on raised ridges in the experimental farm of ND University of Agriculture and Technology Kumarganj Faizabad in early March. The ridge to ridge distance was $70 \mathrm{~cm}$ and rhizome to rhizome distance was kept at $30 \mathrm{~cm}$. The field plot used had sandy loam soil containing NPK as 70, 12 and $150 \mathrm{~kg} / \mathrm{ha}$, respectively, organic carbon at $0.25 \%$ and $\mathrm{pH} 7.8$. The fertilizers were applied at the time of sowing at the rate of $80 \mathrm{~kg} / \mathrm{ha}$ phosphorus, $60 \mathrm{~kg} / \mathrm{ha}$ potash and $100 \mathrm{~kg} / \mathrm{ha}$ urea. Another dose of urea at the equal rate was applied two months after sowing of the rhizomes. The design of the planting was randomized block with three replications.

\section{Observation methodology}

The crop was allowed to grow for about 38 weeks and harvested in late December. Three randomly chosen plants were harvested for each genotype per replication. The root system was washed in running water. The observations on the morphological features and organ yields were recorded on single plants, which included height and number of leaves and rhizomes. The leaves and rhizomes were separated and weighed to obtain their fresh weights. The chemical characterization of leaves and rhizomes was done on the replication-wise pools of three plants per genotype. For this purpose, the pools of leaves and rhizomes were cut into small pieces separately to draw random samples for analysis.

\section{Essential oil estimation and characterization}

The samples of leaves and rhizomes were hydro-distilled in Clevenger's type apparatus at $65^{\circ} \mathrm{C}$ for $3 \mathrm{~h}$ to estimate per cent essential oil content. The genotype- and replication-wise oil yields of leaves and rhizomes per plant were calculated by multiplying per cent oil content, specific gravity 0.9 and the average weight of leaves or rhizome material per plant divided by 100 . The oil samples were analyzed for the contents of major terpenoids using gas liquid chromatography. The GC analysis on the neat oil samples was accomplished on HP-5890 Series-II gas chromatograph using a $3 \mathrm{~m} \times 3 \mathrm{~mm}$ SS column packed with $3 \%$ AT-1000 on $80 / 100$ supelcoport and FID as detector. Oven temperature was programmed from $100^{\circ} \mathrm{C}$ to $220^{\circ} \mathrm{C} @ 5 \% \mathrm{~min}$ with initial and final temperature hold of 2 and $5 \mathrm{~min}$, respectively. Nitrogen gas was used as carrier @ 30 $\mathrm{ml} / \mathrm{min}$ : injector and detector temperatures were set at $200^{\circ} \mathrm{C}$ and $240^{\circ} \mathrm{C}$, respectively. Data were processed in HP-339G Series III integrator.

\section{Estimation of curcumin content}

The percent curcumin content was detected in the freshly harvested rhizomes as well as in the rhizome material left over following essential oil extraction by hydro-distillation. 
The procedure of Gupta et al., (1999) was followed after minor modifications (Gupta $e t$ al., 1999). For each curcumin extraction, in the airdried and powdered $0.2 \mathrm{~g}$ rhizome sample $10 \mathrm{ml}$ of acetone was added and incubated for $12 \mathrm{~h}$, filtered and the filtrate was evaporated. The residue extract was redissolved in $2 \mathrm{ml}$ of acetone for quantification. The curcumin was estimated by thin layer chromatography. The TLC was performed on a pre-activated $\left(100^{\circ} \mathrm{C}\right)$ silica gel TLC plate ${ }^{60} \mathrm{~F}_{254} 10 \times 10 \mathrm{~cm}$. Samples and standards were applied to the plate as $6 \mathrm{~mm}$ wide bands with an automatic TLC applicator Linomate IV under $\mathrm{N}_{2}$ flow (Camag, Muttenz, Switzerland), $10 \mathrm{~mm}$ from the bottom of the plate at a delivery speed of the syringe $10 \mathrm{~s} / \mu \mathrm{L}$.

The application parameters were identical for the analyses performed. The plate was developed using mobile phase chloroform : methanol :: $95: 5$ and the spots were scanned at $366 \mathrm{~nm}$ using the absorption/ reflection detection mode; RF of curcumin was 0.69 .

\section{Results and Discussion}

Wide variability was observed in the genotypes for all the characters studied (Table 1,2 and 3). The salient features of the variability are described below.

\section{Leaf}

Number of leaves borne on turmeric plant is indicative of its vigour. It will be seen from Table 1 that the genotypes produced 2 to 85 leaves on their plants (mean $=21.8$ ). The fresh weight of leaves varied between $15 \mathrm{~g}$ and 4.3 $\mathrm{kg}$ (mean $=0.8 \mathrm{~kg})$. The oil content in the fresh leaves varied between $0.05 \%$ and $0.83 \%$ (mean $=0.48 \%)$ and the essential oil yield varied between 0.1 and $28 \mathrm{~g}$ per plant (mean = $3.67 \mathrm{~g}$ ). Considering all the genotypes together, it will be seen from Table 4 that the leaf mass was highly correlated with plant height with ( $\mathrm{r}$
$=0.62)$. Further, the leaf oil yield had strong correlation with leaf mass $(\mathrm{r}=0.91)$.

The leaf essential oil from the genotypes also differed widely in the composition (Table 2). The known major terpenoids of turmeric leaf oil namely a-pinene, $\mathrm{g}$-terpinene, 1,8-cineole, r-cymene, Ar-curcumene, Ar-turmerone, aturmerone, b-turmerone were present in almost all the genotypes, althoughtoextents. The contents of g-different terpinene, 1,8cineoleandr-cymenedemonstrated very large variability, the range of the concentration of gterpinene was from 0.8 to $62.8 \%$ (mean = $11.8 \%$ ) and that of 1,8-cineole was from 0.01 to $35.5 \%$ (mean $=14.5 \%$ ) and variation ranged from 0.01 to $78.1 \%$ for r-cymene $($ mean $=21.1 \%)$.

The range of $\alpha$-pinene, Ar-curcumene and turmerone(s) was relatively lower; the concentrations of these terpenoids ranged from 0.01 to $17.4 \%$ (mean= $3.0 \%$ ). Their order of occurrence in terms of increasing concentrations was $\alpha$-pinene $<\beta$ - turmerone $<\alpha$ turmerone $<\mathrm{Ar}$-curcumene $<\mathrm{Ar}$-turmerone. The pooled concentration of the three turmerone(s) varied from 0.03 to $18.2 \%$ (mean $=9.8 \%$ ) among all the genotypes. It is noteworthy that the concentrations of the $\alpha$-pinene, Arcurcumene and Ar-turmerone were very low $(<0.01 \%)$ in the essential oil of the genotype designated as NDH-7.

The concentration of Ar-curcumene and all the three turmerones was also observed to be very low in the genotype NDH-98. In the genotype NDH-18 essential oil, concentrations of Arturmerone and $\beta$-tumerone were low and in the essential oil of NDH-45, the concentrations of Ar-curcumene, Arturmerone and $\beta$-turmerone were low. The genotypes NDH-79 and NDH-108 were very low in concentration of o-cymene and Arturmerone, respectively. 


\section{Rhizome}

The genotypes also demonstrated high level of variability for the rhizome characters (Table 1). The number of rhizomes per plant varied from 1 to 129 (mean $=31.5)$ in the genotypes. The rhizome yield per plant varied from $21 \mathrm{~g}$ to $3.5 \mathrm{~kg}$ (mean $=736 \mathrm{~g})$. The oil and curcumin contents in the rhizome varied from 0.05 to $1.4 \%($ mean $=0.57 \%)$ and 0.33 to $1.55 \%$ (mean $=0.80 \%)$, respectively. The oil and curcumin yields varied from 0.1 to $19.9 \mathrm{~g}$ $($ mean $=3.6 \mathrm{~g})$ and 0.2 to $31.0 \mathrm{~g}$ per plant $($ mean $=6.0 \mathrm{~g})$, respectively. The correlations between rhizome mass on one hand and curcumin yield on the other hand and that between rhizome oil yield and curcumin yield were positive and highly significant (Table 4). Interestingly, the correlation between leaf oil yield and rhizome curcumin yield was also positive and significant. The leaf mass was highly positively correlated with rhizome mass (Table 4). Previous work has identified $\alpha$-pinene, $\beta$-pinene, myrcene, 1,8-cineole, $\gamma$ terpinene, o-cymene, linalool, Ar-curcumene, zingiberene, Ar- turmerone, B-turmerone and B- turmerone as the major terpenoids in the rhizome essential oil. The genotypes demonstrated enormous variability in the contents of these compounds in the essential oil (Table 3 ).

The $\alpha$ - pinene, myrcene, Ar-curcumene, Arturmerone and B-turmerone concentrations varied from 0.01 to $45.1 \%$ (mean $=9.3 \%)$, 0.01 to $45.7 \%$ (mean $=3.6 \%$ ), 0.13 to $34.8 \%$ $($ mean $=4.1 \%), 0.01$ to $39.4 \%$ (mean $=$ $11.7 \%), 0.01$ to $34.3 \%$ (mean $=6.7 \%)$, respectively. The variation in the contents of $\alpha$-pinene, 1,8-cineole, $\gamma$-terpinene, o-cymene, and zingiberene was relatively lower. The concentrations of these terpenoides varied from 0.01 to $14.4 \%$ with mean values ranging from 0.5 to $3.1 \%$. There was more compositional variation in the rhizome essential oils as compared to leaf essential oils. The $\alpha$-pinene, $\beta$-pinene, myrcene, 1,8cineole, B-terpinene, o-cymene, linalool, zingiberene, Ar-turmerone, $\alpha$-turmerone and B-turmerone concentrations was very low in the rhizome oils of a total of $23,22,31,29$, $41,27,1,1,1,1$ and 1 out of 17 genotypes, respectively.

\section{Recovery of curcumin from hydro-distilled rhizomes}

The hydro-distilled rhizomes of all the genotypes were extracted for curcumin. The curcumin contents of the fresh and hydrodistilled rhizomes were compared genotype wise. The results presented in Table 5 show that curcumin is extractable from the hydrodistilled rhizomes to different extents in different genotypes. Whereas in rhizomes of many genotypes with $<50 \%$ of curcumin present in fresh rhizomes was extractable from hydro -distilled rhizomes, in the other genotypes such as NDH-98 and NDH-74, bulk of the curcumin (> 80\%) that was present in the fresh rhizomes was extractable from the hydro-distilled rhizome counterparts.

\section{Identification of genotyeps for high curcumin and leaf oil yields}

In Figure 2, the genotypes are plotted as metroglyphs with curcumin yields on one hand and leaf oil yield on the other hand. The concentrations of $\gamma$-terpinene, 1,8-cineole, ocymene of the leaf oil and per cent content of oil, $\alpha$-pinene and turmerone contents of the rhizomes are depicted as bars on the metroglyphs. This analysis identified the genotypesNDH-18, NDH-98, NDH-74 and $\mathrm{NDH}-7$ as high yielding resources for curcumin on the one hand and leaf oil on the other hand. The leaf oils of these genotypes were relatively rich in o-cymene, pinene(s) and turmerones. 
Table.1 Variation in essential oil yield characters of leaves and rhizomes of turmeric Curcuma longa

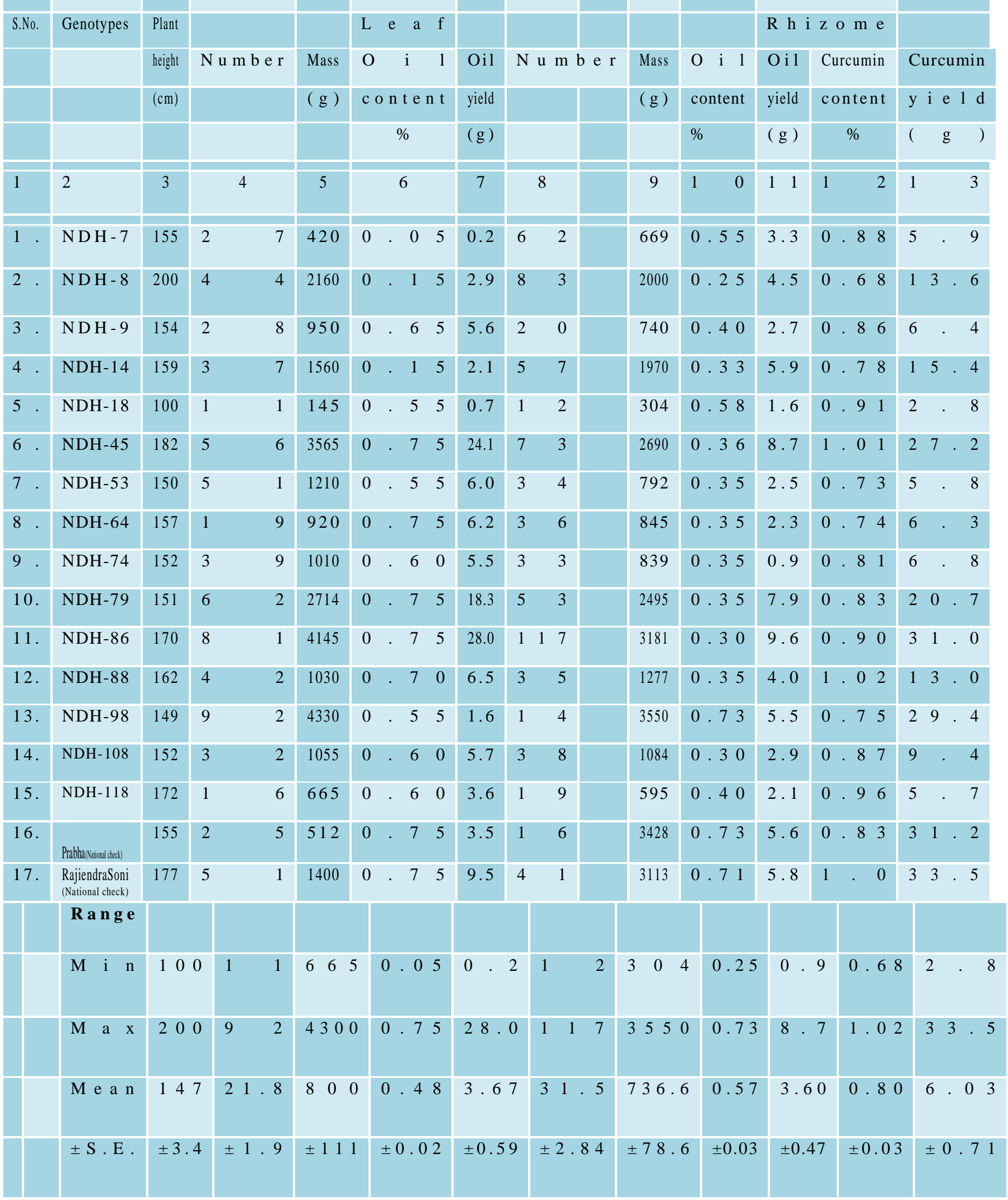


Table.2 Percentage composition of major terpenoids in leaf essential oil of different genotypes of turmeric Curcuma longa

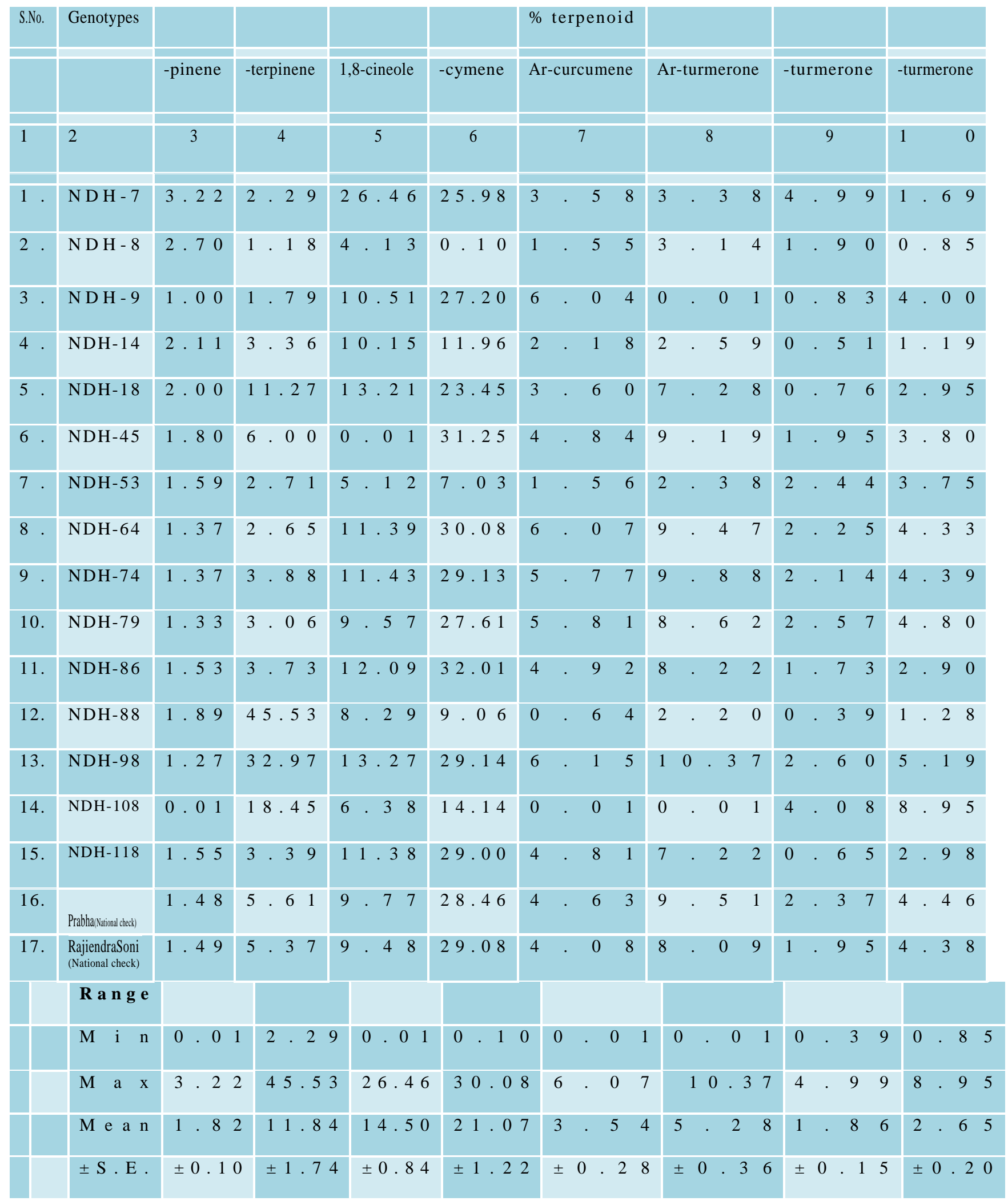


Table.3 Per cent composition of major terpenoides in rhizome essential oil of different genotypes of turmeric Curcuma longa

\begin{tabular}{|c|c|c|c|c|c|c|c|c|c|c|c|c|c|}
\hline \multirow{2}{*}{ S.No. } & \multirow[t]{2}{*}{ Genotypes } & \multirow[b]{2}{*}{-} & \multirow[b]{2}{*}{-} & \multirow[b]{2}{*}{ Myr- } & \multirow[b]{2}{*}{$1,8-$} & \multirow[b]{2}{*}{ g-terpi- } & $\%$ terpenoid & \multirow[b]{2}{*}{ lina- } & & \multirow[b]{2}{*}{ zingi- } & \multirow[b]{2}{*}{ A $\mathrm{r}-$} & \multirow[b]{2}{*}{-} & \\
\hline & & & & & & & \multirow{2}{*}{$\begin{array}{l}\mathrm{p} \\
\text { cymene }\end{array}$} & & & & & & \\
\hline & & pinene & pinene & cene & cineole & nene & & lool & $\begin{array}{l}\text { A r - } \\
\text { c urcu- }\end{array}$ & \multicolumn{3}{|c|}{ bereneturme- turme- } & \\
\hline & & & & & & & & & $\mathrm{m}$ ene & & ron e & \multicolumn{2}{|l|}{ rone } \\
\hline 1 & 2 & 3 & 4 & 5 & 6 & 7 & 8 & 9 & & 11 & 12 & 1 & \\
\hline 1 & NDH-7 & 0.20 & 6.38 & 0.01 & 2.86 & 0.70 & 0.47 & 1.18 & 2.16 & 2.29 & 5.59 & 7.96 & \\
\hline 2 & NDH-8 & 2.98 & 0.38 & 0.94 & 0.01 & 0.01 & $\begin{array}{llll}0 & . & 0 & 1\end{array}$ & 1.48 & 1.69 & 2.84 & 3.80 & 8.34 & \\
\hline 3 & NDH-9 & 0.55 & 0.01 & 41.78 & 7.02 & 1.03 & 1.97 & 0.24 & 1.19 & 0.95 & 7.51 & 9.55 & \\
\hline 4 & NDH-14 & 0.01 & 0.01 & 45.67 & 9.57 & 1.20 & 1.68 & 0.23 & 1.35 & 0.82 & 5.25 & 7.70 & \\
\hline 5 & NDH-18 & 0.32 & 14.13 & 2.13 & 0.04 & 0.01 & 0.17 & 1.08 & 4.08 & 1.93 & 36.68 & 13.45 & \\
\hline 6 & NDH-45 & 0.60 & 0.01 & 20.91 & 3.46 & 0.43 & 0.55 & 0.28 & 1.71 & 1.24 & 10.86 & 14.41 & \\
\hline 7 & NDH-53 & 0.49 & 20.01 & 2.38 & 0.41 & 0.45 & 0.21 & 0.31 & 1.99 & 1.23 & 14.11 & 15.83 & \\
\hline 8 & NDH-64 & 1.01 & 32.96 & 0.01 & 7.72 & 0.95 & 1.61 & 0.40 & 1.10 & 1.66 & 5.77 & 10.81 & \\
\hline 9 & NDH-74 & 1.42 & 41.67 & 9.08 & 0.92 & 8.80 & $\begin{array}{llll}0 & 0 & 0 & 1\end{array}$ & 0.22 & 0.96 & 0.77 & 16.22 & 7.87 & \\
\hline 10. & NDH-79 & 1.17 & 45.05 & 7.70 & 1.10 & 1.92 & 1.70 & 0.32 & 1.33 & 0.92 & 21.30 & 8.51 & \\
\hline 11. & NDH-86 & 0.88 & 20.80 & 5.53 & 0.31 & 7.06 & $\begin{array}{llll}0 & . & 0 & 1\end{array}$ & 0.31 & 1.13 & 0.13 & 6.67 & 13.83 & \\
\hline 12. & NDH-88 & 0.33 & 10.98 & 0.01 & 4.36 & 8.66 & $\begin{array}{llll}0 & 0 & 0 & 1\end{array}$ & 0.29 & 0.30 & 1.21 & 18.96 & 15.01 & \\
\hline 13. & NDH-98 & 5.93 & 0.01 & 0.01 & 0.01 & 0.01 & $\begin{array}{llll}0 & 0 & 0 & 1\end{array}$ & 1.42 & 0.91 & 0.01 & 32.22 & 19.49 & \\
\hline 14. & NDH-108 & 1.26 & 40.20 & 0.01 & 6.74 & 1.05 & 2.18 & 0.22 & 1.15 & 0.83 & 7.35 & 9.57 & \\
\hline 15. & NDH-118 & 0.43 & 14.47 & 0.01 & 5.08 & 0.75 & 0.89 & 0.25 & 1.40 & 0.98 & 6.94 & 11.65 & \\
\hline 16. & 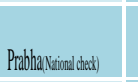 & 0.01 & 13.62 & 0.01 & 5.20 & 12.80 & $\begin{array}{llll}0 & 0 & 1\end{array}$ & 0.37 & 0.17 & 1.25 & 14.04 & 13.25 & \\
\hline 17. & $\begin{array}{l}\text { RajiendraSoni } \\
\text { (National check) }\end{array}$ & 0.80 & 33.61 & 4.84 & 1.03 & 2.27 & 1.53 & 1.55 & 1.41 & 1.06 & 15.76 & 8.19 & \\
\hline & Range & & & & & & & & & & & & \\
\hline & $M \quad \mathrm{i} n$ & 0.01 & $0 \quad .01$ & 0.01 & 0.01 & 0.01 & 0.01 & 0.22 & 0.30 & 0.01 & 3.80 & 7.70 & 3.80 \\
\hline & $M$ a $\mathrm{x}$ & 5.93 & 45.05 & 45.67 & 9.57 & 8.80 & 2.18 & 1.55 & 4.08 & 2.84 & 36.68 & 19.49 & 34.28 \\
\hline & $\mathrm{Me}$ a $\mathrm{n}$ & 0.52 & 9.26 & 3.62 & 1.46 & 1.17 & 0.95 & 1.85 & 4.08 & 3.14 & 11.66 & 8.80 & 6.66 \\
\hline & $\pm S . E$ & \pm 0.10 & \pm 1.23 & \pm 0.84 & \pm 0.24 & \pm 0.28 & \pm 0.19 & \pm 0.24 & \pm 0.56 & \pm 0.29 & \pm 0.94 & \pm 0.49 & \pm 0.57 \\
\hline
\end{tabular}

Fig.1 Features of Curcuma longa plants. $\mathrm{A}=$ Rhizomes; $\mathrm{B}=$ Inflorescence; $\mathrm{C}=$ Whole plant; $\mathrm{D}=$ Plantation

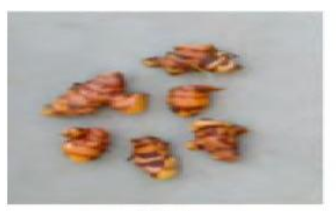

(A)

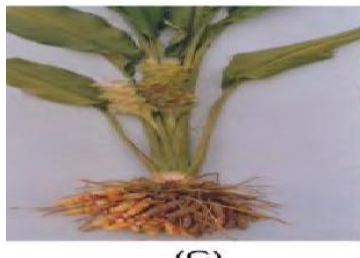

(C)

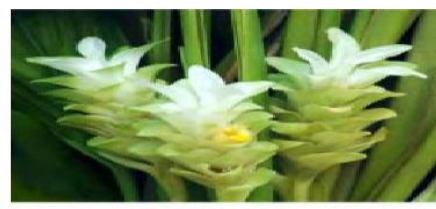

(B)

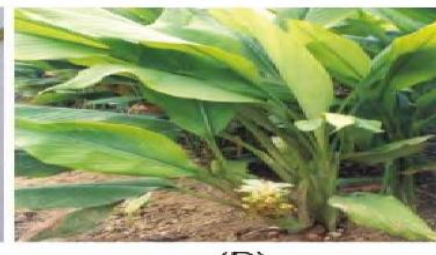

(D) 
Fig.2 Genotypes of turmeric Curcuma longa represented as metroglyphs depicting genotype wise variation in chemical characteristics of rhizomes and leaves
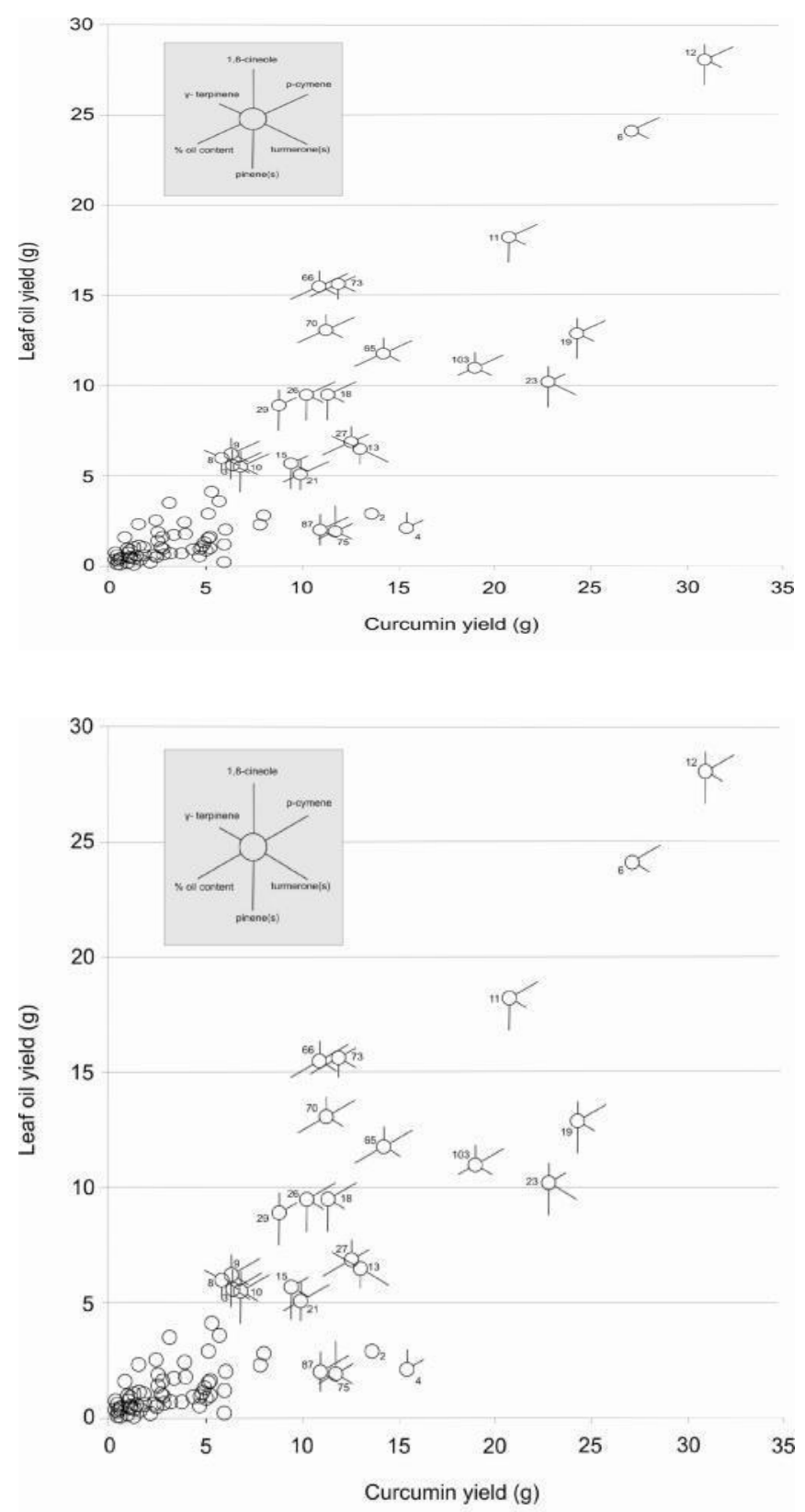

The results of the comparative analysis of economic characters of turmeric $C$. longa genetic resources from northern India described above demonstrate very large variability among the genotypes. This is commensurate with the belief that $C$. longa was domesticated into a crop in the Asian region, more particularly in India.
In an earlier study, C. longa cv. Prabha (National check) which is cultivated widely in Southern India was characterized for the yields of rhizomes and leaves and their essential oils (Bansal et al., 2002). Several genotypes of the present study out yielded this cultivar and some of the other cultivars grown in India and other parts of Asia (Dixit et al., 
2000; Nandi, 1991; Panigrahi et al., 1987; Paramasivam et al., 2009; Pathana et al., 1988; Philip and Nair, 1983; Rama Rao and Rao, 1994; Randhawa and Mahey, 1988). The yields of rhizomes of $C$. longa (cv Roma) and other varieties have been reported earlier in the range of $100 \mathrm{~g}$ to $700 \mathrm{~g}$. In this study, 22 genotypes yielded rhizomes in more than $1 \mathrm{~kg}$ quantity per plant. In the present experiment, the yield of rhizomes in cv Prabha (National check) was $1.9 \mathrm{~kg}$. Six genotypes namely NDH-7, NDH-9, NDH-18, NDH-45, NDH-79 and NDH-98 gave rhizome yield of $>2$ $\mathrm{kg} / \mathrm{plant}$. Among these the genotype NDH-18 gave a rhizome yield of $3.5 \mathrm{~kg} / \mathrm{plant}$. The genotype NDH-98, produced $4.1 \mathrm{~kg}$ leaf biomass per plant which is marginally less than $4.3 \mathrm{~kg}$ biomass produced by plants of Rajendra Sonia (National check) However, the genotype NDH-7, proved superior to genotypes $\mathrm{NDH}-45$, in terms rhizome oil yield (18.2 g/plant for NDH-74. Some other genotypes recorded roughly similar yields of essential oils from leaves and rhizomes, e.g. $\mathrm{NDH}-18$ (15.6 $\mathrm{g}$ from leaves vs $17.0 \mathrm{~g}$ oil from rhizomes). Although the correlation coefficients in the 17 genotypes between leaf oil yield and rhizome oil yield, leaf oil yield and curcumin yield, rhizome oil yield and curcumin yield were positive and significant, yet some of the genotypes showed large differences between the characters found highly correlated on the population basis. Clearly the genetic resources of $C$. longa studied here offer potential for breeding varieties of $C$. longa for better yields of rhizomes rich in curcumin and essential oils capable of producing large biomass of leaves rich in essential oil making them resource not only of rhizomes but also of leaf essential oil.

The leaf and rhizome essential oils of different genotype demonstrated large variability in their terpenoid composition. There were several genotypes in which one of the terpenoids could be identified as a major component for leaf and rhizome essential oil since it was present in excess of $30 \%$ of the total terpenoids. Such genotypes could be called as chemotypes of the concerned terpenoid component. The genotype NDH-14, and NDH-18 would thus be termed as myrcenechemotypes because their rhizome essential oils contained 41.8 and $45.7 \%$ myrcene, respectively. The genotypes NDH45, NDH-79, NDH-18, NDH-74 produced rhizome essential oils that were richer than $30 \%$ in B-pinene, making them Bpinenechemotypes. The genotype NDH-98 was a Ar-curcumene chemotype as its rhizome oil contained Ar-curcumene @ 35\%. The genotype NDH-86, NDH-64 and NDH53 proved to be Ar-turmerone chemotypes. The genotype NDH-14, NDH-18, NDH-45, NDH-74, NDH-79, Prabha and R.Sonia which could be termed as turmerone(s) rich chemotypes because their rhizome essential oils contained Ar-, $\alpha-$, and $\beta$ - turmerone in $>30 \%$ contents. Generally, the turmerones comprised a marker of turmeric essential oils. Surprisingly, the turmerone content in the rhizome essential oils of NDH-53 was negligible $(0.03 \%)$. This accession perhaps represents a natural mutation of one or more steps involved in turmerone biosynthesis in rhizomes. This conclusion is supported by the observation that turmerones are also deficient in leaf essential oil of this genotype. The $\alpha$ and $\beta$-pinene, myrcene, 1, 8-cineole, $\gamma$ terpinene, $\rho$-cymene, linalool, zingiberene, Ar-turmerone, $\alpha$ - turmerone and $\beta$-turmerone had been identified as major components of rhizome essential oil on the basis of previous work (Garg et al., 1999; Jantan et al., 1999; Marongiu et al., 2002; Nigam and Ahmad, 1991; Sharma et al., 1997). Indeed these together comprised more than $1 / 3$ terpenoid components in the rhizome essential oil of the large majority of genotypes studied, however, there are some genotype, e.g. NDH-9, NDH53, NDH-64, NDH-88 and NDH-108 in which the above listed terpenoids did not 
constitute even $1 / 3$ of the total terpenoid composition of the rhizome essential oil. The rhizomes of all the genotypes contained curcumin though to different extents.

The richness of specific terpenoids in the leaf essential oil could also be the criteria for identification of chemotypes among genotypes. In this regard, the genotypes NDH-98, Prabha, R.Sonia, NDH-74 and NDH-18 appeared as $\gamma$-terpinenechemotypes since their leaf essential oil contained concerned compound $\gamma$-terpinene in 32.8 to $62.8 \%$ concentrations. The genotype NDH-98 and NDH-18 proved to be 1,8-cineole chemotypes because their leaf essential oil contained 1,8-cineole in $34.9 \%$ and $35.5 \%$ concentrations, respectively.

An interesting question answered in this work was whether the rhizomes could be extracted for both essential oil and curcumin, first for essential oil and subsequently for curcumin. The results ascertained the feasibility of such technology on the rhizome of some of the genotypes. The genotype NDH-74 and NDH98 proved to be amenable for the dual production from the rhizome.

\section{Concluding Remarks}

Following is the outcome in the form of new knowledge and materials from the evaluation of 17 genetic resources of $C$. longa in the present study. The $\gamma$-terpinene, 1,8-cineole and $\rho$-cymene are present in the leaf essential oil in high amounts and pinene(s), myrcene, Ar-curcumene and turmerones in the rhizome essential oil. Turmerones and/or curcumene in the rhizomes are the markers for $C$. longa. There exist in $C$. longa, $\gamma$ - terpinene, 1,8cineole and $\rho$-cymene chemotypes on account of their richness in leaf essential oils and $\beta$ pinene, myrcene, Ar- curcumene and turmeronechemotypes for their high concentrations in the rhizomes essential oil.
There are genotypes which hyper-yield leaf essential oil and curcumin rich rhizomes. Perusal of direct selection among the genetic resources and genetic manipulation via mutagenesis, transgenesis and conventional plant breeding procedures have potential for cultivar development to obtain products of defined chemical composition.

\section{Acknowledgements}

Grateful thanks are due to officials of Centre of Advanced Studies, Department of Crop Physiology and Department of Vegetable Science of N.D. University of Agriculture and Technology, Kumarganj Faizabad and Senior Scientists of Indian Institute of Pulses Research Kalyanpur Kanpur for sparing me in finalization of this Research paper.

\section{References}

Bansal R P, Bahl J R, Garg S N, Naqvi A A and Kumar $S$ Differential chemical composition of the essential oil of the shoot organs, rhizomes and rhizoids in the turmeric Curcuma longa L. grown in Indo-Gangetic plains Pharma Biol., 40(2002) 384-389

Bhutani M K, Bishnoi M and Kulkarni S K Anti-depressant like effect of curcumin and its combination with piperine in unpredictable chronic stress-induced behavioural, biochemical and neurochemical changes Pharma Biochem Behav., 92(2009) 39-43

Dixit D, Srivastava N K and Kumar R Intraspecific variation in yield capacity of turmeric Curcuma longa with respect to metabolic translocation and partitioning of ${ }^{14} \mathrm{C}$ photo assimilate into essential oil and curcumin. $J$ Med andArom Pl Sci22/23(2000) 269-274

Garg S N, Bansal R P, Gupta M M and Kumar $S$ Variation in the rhizome essential oil and curcumin contents and 
oil quality in the land races of turmeric Curcuma longa of north Indian plains Flav. Fragr. J., 14(1999): 315-318.

Gupta A P, Gupta M M and Kumar S Simultaneous determination of curcuminoids in Curcuma samples using high performance thin layer chromatography J Liq Chromed and Rel. Technol., 22(1999) 1561-1569.

Jang E, Choi M, Jung U J, Kim M, Kim H, Jeon S, Shin S, Seong C and Lee M Beneficial effects of curcumin on hyperlipidemia and insulin resistance in high-fat-fed hamsters Metabolism., 57 (2008) 1576-1583.

Jantan I B, Ahmad A S, Ali N A M, Ahmad A $\mathrm{R}$ and Ibrahim $\mathrm{H}$ Chemical composition of the rhizome oils of four Curcuma species from Malaysia $J$ Essen Oil Res11 (1999) 719-723.

Khanna N M Turmeric-Nature's precious gift Curr. Sci., 76 (1999) 1351-1356.

Kunnumakkara A B, Anand P and Aggarwal B B Curcumin inhibits proliferation, invasion, angiogenesis and metastasis of different cancers through interaction with multiple cell signaling proteins Cancer Lett., 269(2008): 199-225.

Liang G, Shao L, Wang Y, Zhao C, Chu Y, Xiao J, Zhao Y, Li $X$ and Yang $S$ Exploration and synthesis of curcumin analogues with improved structural stability both in vitro and in vivo as cytotoxic agents Bioorg. Med. Chem., 17 (2009): 2623-2631.

Lin S, Huang H, Yang J, Wu J, Hsai T, Lin C, Lin C, Kuo C, Wood W G and Chung J DNA damage and endoplasmic reticulum stress meditated curcumininduced cell cycle arrest and apoptosis in human lung carcinoma A-549 cells through the activation caspases cascadeand mitochondrial-dependent pathway Cancer Lett., 272(2008): 77-90.

Marongiu B, Poreedda S, Caredda A, Gioannis B D and Piras A Supercritical
$\mathrm{CO}_{2}$ extraction of curcumin and essential oil from the rhizomes of turmeric (Curcuma Longa L.) JEOBPS 5(2002): 144-153.

Moon D, Kim M, Lee H, Choi Y H, Park Y, Heo M and Kim G Curcumin attenuates ovalbumin- induced airway inflammation by regulating nitric oxide Biochem and Biophys Res Commun., 375(2008) 275-279.

Nandi A Genetic variability in turmeric (Curcuma longa) Indian J Agril. Sci., 61(1991) 941-942.

Nigam M C and Ahmed A Curcuma longa: Terpenoid composition of its essential oil Indian Perfumer., 35 (1991) 255257.

Panigrahi U C, Patro G K and Mohanty G C Package of practices for turmeric cultivation in Orissa Indian Farming37 (1987) 4-6.

Paramasivam M, Poi R, Banerjee $\mathrm{H}$ and Bandyopadhyay A High performance thin layer chromatographic method for quantitative determination of curcuminoids in Curcumalonga germplasm Food Chem113(2009) 640644

Pathana N K, Arya P S and Singh M Variability studies in turmeric (Curcuma longa L.)Indian $J$ Agril Res22 (1988) 176-178

Philip J and Nair P C S Morphological and yield characters of turmeric types Indian Cocoa Arecanut Spices J., 6(1983): 61-67.

Pisano M, Cossu S, Sassu I, Pagnan G, Fabbri D, Dettori M A, Palmieri G, Delogu G, Ponzoni M and Rozzo C New curcumin analogues show enhanced antitumour activity in malignant melanoma cells European J Cancer, 6(2008): 90.

Rama Rao M and Rao D V R (1994) Genetic resources of turmeric, In: Advances in Horticulture Plantation and Spice crops, Part 1 (Eds: Chanda KL and Rethinam 
P), pp 131-149, Malhotra Publication, New Delhi.

Randhawa G S and Mahey R K (1988) Advances in the agronomy and production of turmeric in India. In: Herbs, Spices and Medicinal Plants. Recent Advances in Botany, Horticulture and Pharmacology (Eds: Cracker LE and Simon JE), pp. 71-101,
Oryx, New York

Sharma R K, Mishra B P, Sarma T C, Bordoloi A K and Pathak M G Essential Oils of Curcuma longa L. from Bhutan J Essen Oil Res., 9(1997): 589-592

Srimal R C Turmeric: a brief review of medicinal properties. Fitoterapia, LXVIII (1997) 483-493.

\section{How to cite this article:}

Mudit Srivastava. 2018. Physio-Biochemical basis of Yield and Quality Variation in Turmeric (Curcuma longa L.) Genotypes. Int.J.Curr.Microbiol.App.Sci. 7(03): 3696-3707. doi: https://doi.org/10.20546/ijcmas.2018.703.428 